\title{
The Impact of Urban Noise on the Behavior of Two Mouse Species Belonging to the Genus Apodemus
}

\author{
Agnieszka Pieniążek¹, Paweł M. Boguszewski², Robert A. Meronka ${ }^{1 *}$ \\ ${ }^{1}$ Department of Ecology, Faculty of Biology, Biological and Chemical Research Centre, University of Warsaw, Warsaw, Poland \\ ${ }^{2}$ Laboratory of Animal Models, Neurobiology Centre, Nencki Institute of Experimental Biology of Polish Academy of Sciences, \\ Warsaw, Poland \\ Email: *meron@biol.uw.edu.pl
}

How to cite this paper: Pieniążek, A., Boguszewski, P.M. and Meronka, R.A. (2017) The Impact of Urban Noise on the Behavior of Two Mouse Species Belonging to the Genus Apodemus. Natural Resources, 8, 55-68.

https://doi.org/10.4236/nr.2017.82004

Received: December 27, 2016

Accepted: February 5, 2017

Published: February 8, 2017

Copyright $\odot 2017$ by authors and Scientific Research Publishing Inc. This work is licensed under the Creative Commons Attribution International License (CC BY 4.0).

http://creativecommons.org/licenses/by/4.0/

\begin{abstract}
Traffic noise was tested as a stress factor in an open-field study of urban and non-urban populations of two species belonging to the genus Apodemus: the striped field mouse and the yellow-necked mouse. The striped field mouse has inhabited green areas in cities for years, whereas the yellow-necked mouse was first observed in such areas relatively recently. Behavioral reactions to noise in the urban population of striped field mice were the same as the reactions observed in the non-urban population of the species. As for the yellow-necked mouse, behavior in response to noise in the non-urban population differed from that observed in the urban population. We see such differences as being related to the fact that striped field mice, which have inhabited urban areas for many generations, form a stable population in urban areas, and specific individuals are adapted to urban conditions. Yellow-necked mice, in turn, form no stable urban population and the individuals found in cities are most probably migrants, not adapted to urban conditions, which is the reason why their reaction to noise differs from the typical response.
\end{abstract}

\section{Keywords}

Apodemus, Behavior, HPA, Urbanisation

\section{Introduction}

Present-day cities are inhabited by a wide array of animal species. Characterized by milder climate conditions than non-urban environments, cities are warmer than the surrounding areas and have smaller diurnal and seasonal temperature variations [1]. Cities are also places where many species find rich sources of anthropogenic foods [2]. Consequently, breeding seasons may be extended as a 
result of their earlier onset and longer duration [3]. However, taking advantage of what cities have to offer also necessitates coping with inconveniences typical of urban areas. Urban patches inhabited by animals are often small in size, fragmented, and separated by barriers that limit migration possibilities [4]. Human proximity and activity, even if not dangerous as such, may be perceived by animals as threatening [5]. Traffic noise, which is a typical characteristic of cities, acts as a powerful disturbance factor [6]. Characterized by constant high intensity, such noise is present throughout the daytime and often also during the night. Noise with such parameters is believed to act as a major stress factor [7].

The typical reaction to such factors involves a stress response: the activation of the hypothalamic-pituitary-adrenal axis (HPA axis), which results in the release of glucocorticoids into the blood. The peripheral effects of these hormones involve increasing the efficiency of the organism as well as preparing it to cope with greater load and defend itself against actual or predicted threats. In addition to peripheral effects, glucocorticoids also affect the central nervous system through glucocorticoid receptors present in different regions of the brain [8]. Such actions have significance for regulation and consolidation, affect memory processes, modulate emotional responses, and influence decision-making and behavior control processes [9]. These effects are crucial for adequate reaction to a specific stress factor, depending on the context and memories of earlier experiences [10]. Consequently, stress may affect animal behavior. In addition, exposure to a stress factor that is new or occurs in a new situation may induce a different effect than exposure to one that occurs repeatedly in the life of an animal. Prolonged, constant exposure to stress factors may lead to the exhaustion of the body's resources, in addition to substantially impairing fear control functions.

The striped field mouse (Apodemus agrarius) is found in most of the green areas in Warsaw, Poland. Its presence in Warsaw was first recorded in the nineteenth century [11]. In the early twentieth century, the striped field mouse was described as a species often found in the city [12]. In the latter half of the twentieth century, it became the dominating rodent species found in parks [13] [14] [15], with numerous local populations being found in the present-day area of the city [16] [17]. The striped field mouse mainly inhabits fields, meadows, and wastelands, but it is also found in forests and other areas. The species moves predominantly on the surface of the ground and may be active both during the day and at night. They seek refuge in underground burrows, which they often excavate themselves [18].

Another species of the Apodemus genus found in the green areas in Warsaw is the yellow-necked mouse (Apodemus flavicollis). It was first recorded less than 20 years ago and is less frequently found [19] [20]. In nature, the typical habitats of the species are forests. Yellow-necked mice actively utilize both the floor and the canopy of forests: they are excellent climbers, so they can be found even in tree crowns. They are active predominantly at night and seek refuge in burrows, often also in tree hollows, crevices, and bird nesting boxes [18]. 
Both striped field mice and yellow-necked mice can be currently found in green areas in cities, where they are exposed to the same stimuli. Making efficient use of the resources available in the environment appears to necessitate developing the ability to cope with such stimuli. The yellow-necked mouse is a specialist species that is linked to forest habitats and has a relatively short urban colonization history. The striped field mouse, in turn, is a generalist that can inhabit many different environments. It is competitively weaker than the yellownecked mouse yet has a substantially longer city colonization history. Studies of these two species may help find answers to questions concerning their ability to cope with stress factors in urban habitats.

The purpose of this paper is to examine the impact of traffic noise, as a typical stress factor in the urban environment, on the behavior of small rodents that inhabit green areas in cities. The open field test was therefore used to compare changes in the behavior of individuals from urban and non-urban populations in two species belonging to the genus Apodemus that differed in terms of their city colonization history and ecological relationship.

\section{Material and Methods}

\subsection{Animals}

The tests were conducted on adult individuals of the striped field mouse (Apodemus agrarius) and the yellow-necked mouse (Apodemus flavicollis) species. Animals from the urban environment were trapped in a city park in downtown Warsaw. Animals from the natural environment were live-trapped in areas located around $22 \mathrm{~km}$ away from the city center. There were created four groups of animals (Table 1). Pregnant and lactating females as well as sexually immature individuals were excluded from the tests. It was the reason of lowered size of the A. flavicollis group of urban environment, particularly in examined area number of individuals of this species was small at this time. All the procedures were planned in such a way as to allow the animals to be released at the trapping sites within 14 days of the trappings and minimize their contact with humans.

The captured animals were taken to the laboratory at least seven days before the beginning of tests. They were housed individually in standard cages for rodents and given ad libitum access to food and water. All the cages were fitted with PVC (polivinyl chloride) tubes around $20 \mathrm{~cm}$ long and $4 \mathrm{~cm}$ in diameter, which served as shelters for the mice and were later used to transport them

Table 1. Arrangement of experimental groups, and group size.

\begin{tabular}{ccccc}
\hline & \multicolumn{5}{c}{ Groups } \\
\cline { 2 - 5 } & $(1)$ & $(2)$ & $(3)$ & A. flavicollis \\
Species & \multicolumn{3}{c}{ A. agrarius } & \multicolumn{2}{c}{ Non-urban } \\
Environment & Urban & Non-urban & Urban & 13 \\
Group size & 13 & 13 & 6 & (3) \\
\hline
\end{tabular}


between the cage and the test arena [21]. The animals were kept in a room with a 13:11 photoperiod natural for the season of the year (mid-September). The personnel were kept to minimum in order not to disturb the animals.

After the completion of the tests, all animals were released at the trapping sites.

\subsection{The Open Field Test}

The tests were conducted in a white arena of a rectangular shape $(1 \times 1 \mathrm{~m})$ that was $1 \mathrm{~m}$ high. A speaker was positioned outside of the arena, $20 \mathrm{~cm}$ away from the middle of one of its walls. The arena was illuminated with $920 \mathrm{~nm}$ infrared light. The arena was surrounded by a thick curtain. A digital camera (model: GV-BX1300-3V) operating at infrared wavelengths was mounted centrally above the open field to record the behavior of the animals. The computer used for video recording and the operators were located in a neighboring room.

The tests were carried out between 9 p.m. and 3 a.m. in order to adjust the procedure to the diurnal activity of the test animals. All procedures involving the presence of animals were conducted under dim red light. Before a mouse was placed inside, the arena was cleaned, washed with ethanol, and dried in order to eliminate potential traces of animals previously tested.

All mice were tested individually and only once. Each animal was carried to the arena in the PVC tube from its home cage and placed in the center of the open field. A test lasted a total of 15 minutes and consisted of three five-minute parts. In the first and third part, the camera only recorded the behavior of the animals. In the second part, the sound of traffic noise was additionally played from a specially prepared recording: the level of the sound increased from the background level to around $60 \mathrm{~dB}$ for a period of three minutes and then stayed at this level. At the end of the second part, the sound of an ambulance siren was played for around 5 seconds, ultimately reaching the level of $90 \mathrm{~dB}$ (Figure 1). The volume of the speaker was set prior to the beginning of the tests using a microphone and software for recording animal vocalization and remained unchanged throughout the tests. No vocalizations were recorded during the tests. The background sound level, when no recording was being played, did not exceed $20 \mathrm{~dB}$.

After the completion of the test, the tube from the home cage was placed inside the arena and used to transport the animal back to the cage.

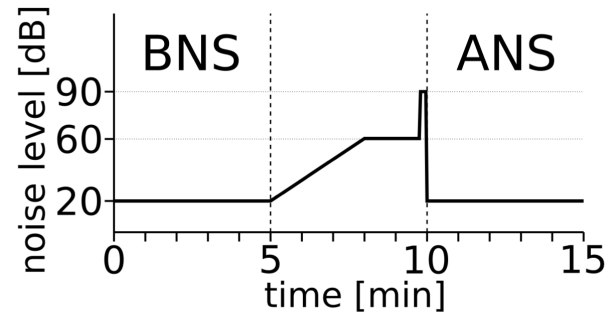

Figure 1. Experiment design. BNS (before noise stimulation) and ANS (after noise stimulation) are parts compared during analysis. 


\subsection{Analysis of the Results of the Open Field Test}

The recordings were analyzed using the EthoVision software based on such parameters as distance moved, average velocity, the time of motion, movement status, and the time spent in the specific sectors of the arena. In addition, the recordings were analyzed in terms of the time spent on grooming, leaning on the wall, rearing, and digging as well as the number of jumps.

Statistical analyses for both species were conducted separately. The results recorded before and after noise stimulation were compared for animals from urban and non-urban populations. A non-parametric Kruskal-Wallis test was conducted. When significant differences were discovered, it was followed by a post-hoc test according to Conover with Holm's adjustment for multiple comparisons. All the analyses were conducted using the $\mathrm{R}$ software [22] and the PMCMR (Pairwise Multiple Comparisons of Mean Rank) library [23].

\subsection{Tests of Glucocorticoid Levels}

Fecal corticosterone levels were measured for all the test animals before and after the open field test. Fecal samples were collected 24 hours before and 8 hours after the test. The animals were placed in cages with steel grid floor with a piece of blotting paper placed underneath. All the feces excreted within two hours were collected and frozen for further analyses.

Corticosterone levels were measured using the enzyme immunoassay kit "Corticosterone EIA," produced by Cayman Chemical (Catalog No. 500651). Extraction and measurements were conducted according to the manufacturer's instructions for the measurement of corticosterone levels in rodent feces.

The results obtained in this way were subjected to a logarithmic transformation and a two-way analysis of variance. The factors were: the timing of sample collection (before and after the test) and the population. The analyses were conducted independently for both species.

\section{Results}

The results are presented for those for which statistically significant differences were found between the phases of the test-for the parameters related to the movement status of the animals, the time of grooming behavior, and the time the animals spent leaning on the walls of the arena.

Time spent on locomotor activity decreased significantly following exposure to noise in the group of both urban and non-urban individuals of $A$. agrarius. For A. flavicollis, in turn, the reaction was only observed in the group of nonurban animals (Figure 2(a)). Similarly, the average velocity and the distance moved were significantly smaller after noise stimulation in urban and non-urban groups of $A$. agrarius. In the groups of $A$. flavicollis, the change was statistically significant only in the group of non-urban mice (Figure 2(b) and Figure 2(c)).

The duration of fast movements did not change between the compared periods and remained low in both groups of $A$. agrarius and A. flavicollis. Nevertheless, a decrease in slow movements and an increase in the periods of freezing 


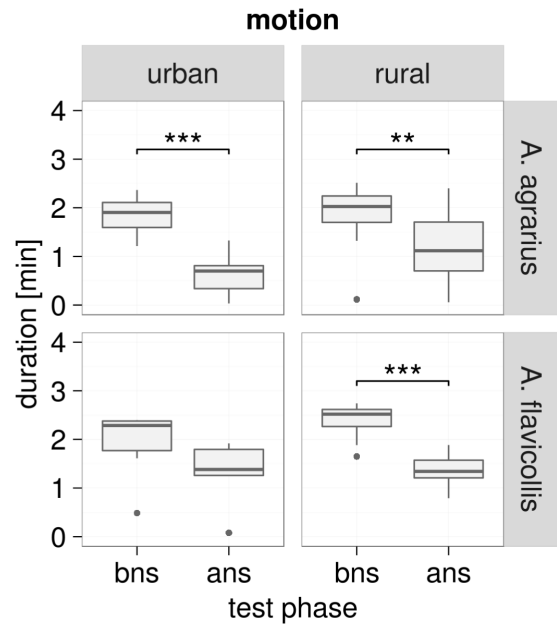

(a)

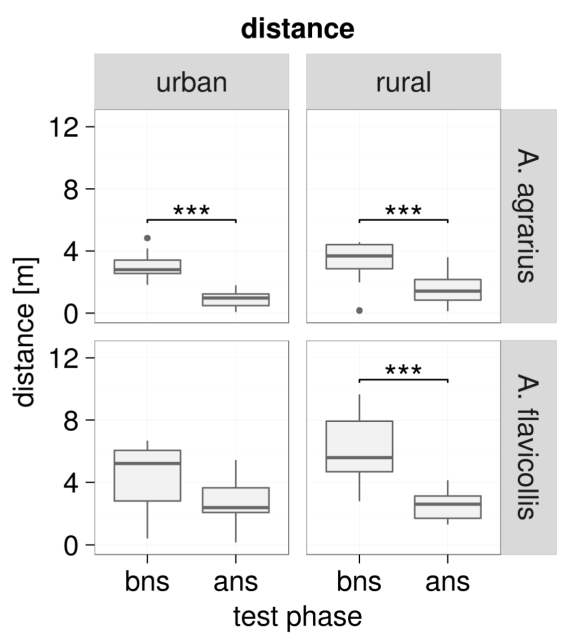

(c)

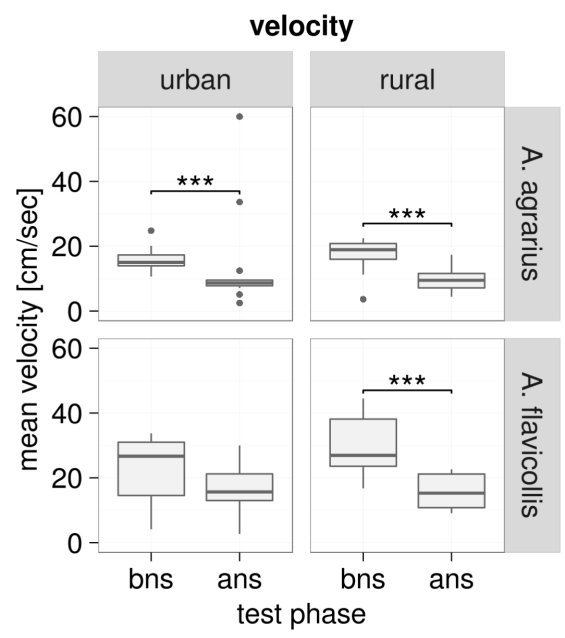

(b)

Figure 2. Parameters of locomotor activity. Results are presented as medians, boxes and whiskers represents quartiles, black dots indicates outliers. Statistical significance marked as follows: ${ }^{\star} p \leq 0.05,{ }^{* *} p \leq 0.01,{ }^{* *} p \leq 0.001$. BNS-before nise stimulation, ANS-after noise stimulation.

behavior before noise stimulation were observed among individuals from the $A$. agrarius species both from the urban environment and from the non-urban environment. In A. flavicollis, a similar change was observed only among individuals from the non-urban environment (Figure 3).

All groups were characterized by the shortest duration of fast movements, which differed significantly from the duration of slow movements and freezing behavior. In the groups of $A$. agrarius from the urban environment and A. flavicollis from the non-urban environment before noise stimulation, the duration of slow movements was significantly longer than the duration of freezing behavior. After noise stimulation, however, the proportion was reversed, with freezing behavior lasting significantly longer than slow movements. In the group of A. agrarius from the non-urban environment before noise stimulation, the duration of slow movements was significantly longer than the duration of freezing behavior, 


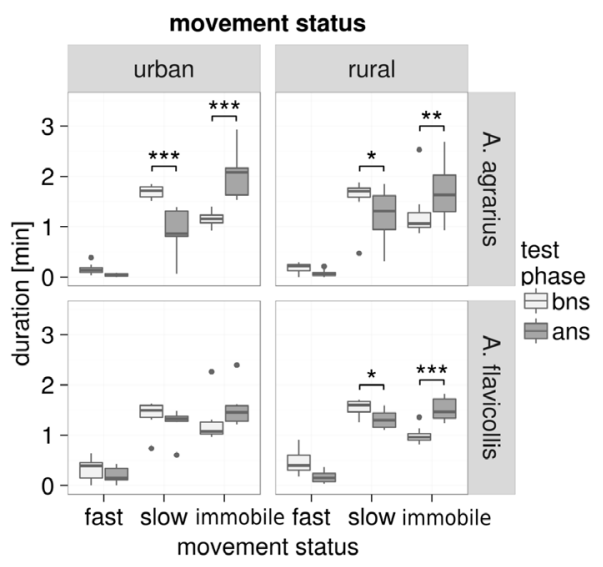

Figure 3. Indicators of movement status. Indications are the same as on the Figure 2.

whereas no significant differences between these two parameters were observed after noise stimulation. In the group of $A$. flavicollis from the urban environment, the duration of freezing behavior and the duration of slow movements did not differ significantly both in the group before noise stimulation and in the one after noise stimulation.

The duration of grooming episodes increased significantly between the phases of the test in the groups of $A$. flavicollis from urban and non-urban environments (Figure 4(a)). The time spent leaning on the walls decreased significantly between test phases in the groups of $A$. agrarius from the urban population and A. flavicollis from the non-urban population (Figure 4(b)).

Comparisons were made between the groups of individuals from urban and non-urban populations for the groups before and after noise stimulation, independently for both species. Individuals from the non-urban population of $A$. agrarius spent significantly more time on locomotor activity following noise stimulation compared to the corresponding group of individuals from the urban population. Also, the total duration of slow movements was significantly longer after noise stimulation among $A$. agrarius from the non-urban population compared to the corresponding group from the urban population. Aside from these two differences, no other significant differences were observed in that comparison.

Jumping and digging were observed in both species of the studied rodents from both populations. These behaviors varied greatly in intensity between specific individuals: some mice showed no behavior of this type during the tests, whereas the behavior of other individuals was characterized by a high level of intensity of jumping and digging. For this reason, the distribution of these parameters was very broad and no statistically significant differences could be reported. In total, the mice from the $A$. agrarius species made 159 jumps, compared with 486 jumps observed among $A$. flavicollis. The cumulative time spent on digging was 26 minutes and 3 seconds for A. agrarius and 6 minutes and 10 seconds for A. flavicollis.

No significant differences were observed in other parameters tested in the study, so for the sake of clarity they are not presented in this paper. 


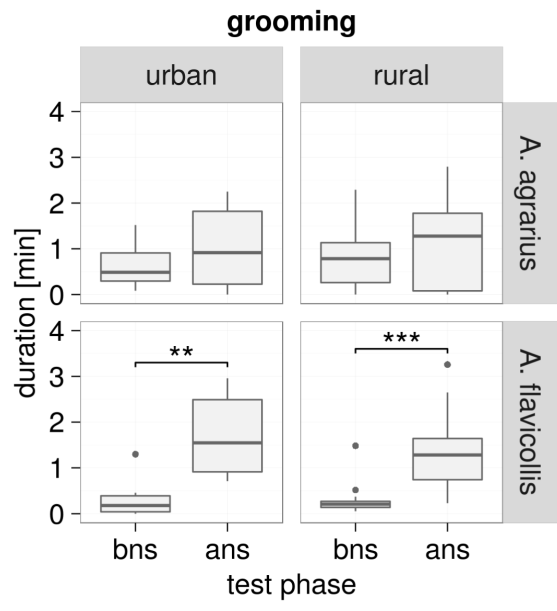

(a)

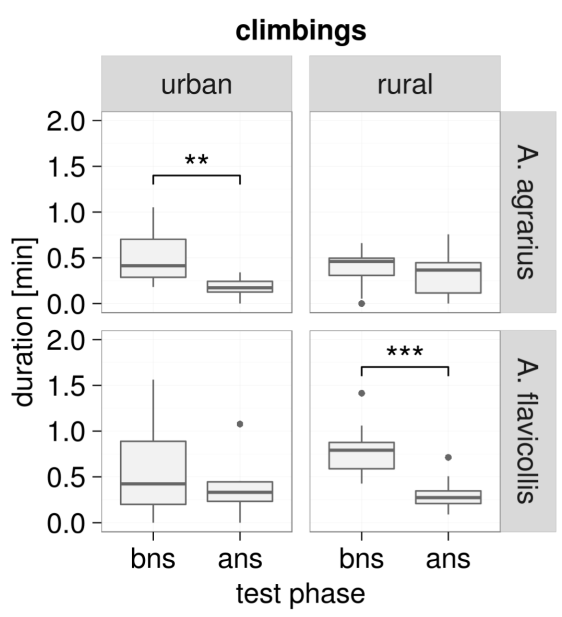

(b)

Figure 4. Parameters of behavior. Indications are the same as on the Figure 2.

Analysis of corticosterone levels lead to the conclusion that none of the tested factors had a significant impact on $A$. agrarius. As for A. flavicollis, one significant factor was the type of the population: the mice from urban populations had higher corticosterone levels compared to the animals from non-urban populations (Figure 5).

\section{Discussion}

The striped field mouse ( $A$. agrarius) has inhabited green areas in cities for around a century, and currently forms stable populations in cities [12] [13] [15]. However, the same cannot be said of A. flavicollis, and it may be presumed that individuals found in urban areas have migrated there from non-urban environments. The results we obtained appear to confirm this hypothesis.

Parameters of locomotor activity decreased over time in most of the groups during the tests, which is typical behavior among rodents. Once placed inside the arena, the animals initially engage in intensive exploration of the surroundings. Over time, they get to know the arena better and explore it less intensively, which is explained by the process of habituation [24] [25] [26] [27]. This can be observed for such parameters as motion, average velocity, and distance. The absence of significant changes in the intensity of locomotor activity between the test phases among A. flavicollis from the urban population and the absence of significant differences compared to corresponding groups from the non-urban population could be attributed to greater diversity in the intensity of the parameters under study, which manifests itself in the broader distribution of results in these groups.

Leaning on the walls of the arena is one of the components of exploration, often referred to as vertical exploratory activity [28]. A decrease in the time spent on such behavior, just like lower locomotion parameters, could be attributed to the gradual exploration of the new environment, which leads to habituation.

Grooming behavior in rodents primarily serves the purpose of body care. In behavioral tests, grooming is linked to fear and, despite numerous ambiguities 


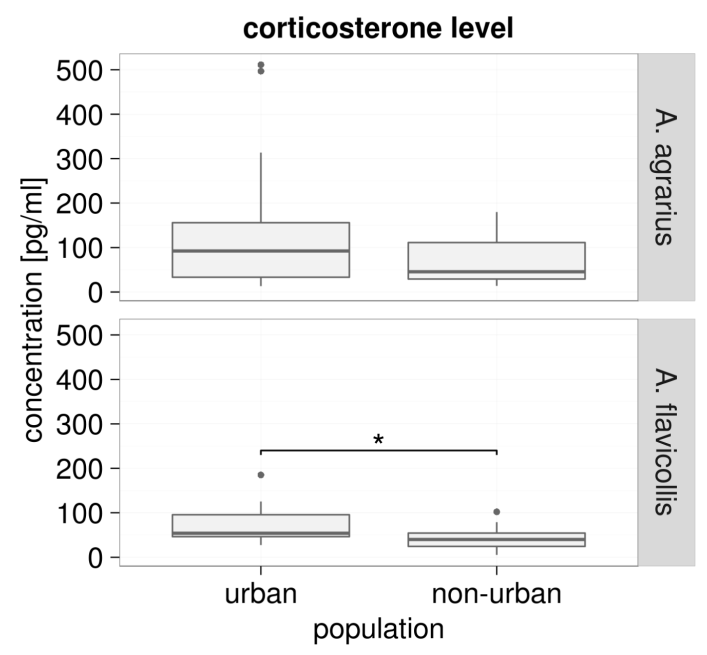

Figure 5. Plot of corticosterone concentraction in fecal samples for signifficant factorpopulation. Indications are the same as on the Figure 2.

and interpretation difficulties [29], it is believed to be a reliable indicator of stress [30] [31] [32]. Although increased time spent on grooming in urban and non-urban populations of $A$. flavicollis in response to noise could be interpreted as reaction to the stress factor, the fact that no change could be observed in either population of $A$. agrarius cannot be interpreted as the absence of stress. Instead, attention should be focused on broad distributions, which proves that the tested mice form a highly diverse group.

Freezing is commonly believed to be a typical example of fear behavior: the mechanism is well-known and directly related to the activation of the HPA axis [9] [32] [33]. The reversal of the proportion of the duration of fast movements to the duration of freezing behavior as a result of noise indicates increased fear levels. Such a situation was observed in the urban and non-urban groups of $A$. agrarius and the non-urban population of $A$. flavicollis. Among individuals from the species $A$. flavicollis, in turn, the duration of freezing remained the same in both phases of the tests and was the same as the duration of slow movements. The result could be interpreted as indicating that the level of fear was the same in both phases of the experiment. Since no significant differences were observed compared to corresponding groups of A. flavicollis from the non-urban environment, it is impossible to say with certainty whether the level of fear in the urban population was high from the outset or the animals did not react to strong noise.

When analyzing the results, we can notice that the nature of significant changes followed a similar pattern for most of the parameters under study in three of the groups of mice belonging to the genus Apodemus, whereas the urban population of $A$. flavicollis showed certain distinctive characteristics. Parameters that reflect locomotor activity indicate that the three aforementioned groups exhibit locomotor habituation typical of the open field test, which cannot be observed for the urban population of $A$. flavicollis. Similarly, this is the only group that exhibited no increase in freezing behavior following noise stimula- 
tion.

Individuals from non-urban groups were trapped in their natural habitats, so the results obtained in these groups can be treated as natural reactions to the stress factor. Similar changes observed in the urban population of $A$. agrarius compared to the non-urban individuals from the same species support the conclusion that individuals from the urban population do not differ from those from the natural population in terms of behavior and react to the stress factor in a way that is typical of the species.

A comparison of the results obtained in the urban population and the non-urban group of $A$. flavicollis provides a different picture, supporting the conclusion that the stress factor reaction among animals from the urban population differs from the reaction that is typical of the species. Such differences can be attributed to the increased activity of the HPA axis, as confirmed by the measurements of the level of the principal hormone of this axis, corticosterone. Corticosterone levels were significantly higher in the animals from the urban population of $A$. flavicollis as compared to the non-urban population. In addition, increased time spent on grooming in response to the stress factor observed in $A$. flavicollis, compared to the absence of this reaction in $A$. agrarius, may suggest greater reactivity to stress in the former species. As mentioned earlier, the activation of the HPA axis, which manifests itself in elevated corticosterone levels, affects behavior, allowing the animal to find an optimal reaction to a stressor. Such influence may be individual in its nature, i.e. different for every animal, which could increase the variance of the observed parameters.

The results obtained in behavioral tests confirm the findings of earlier studies, which support the conclusion that the species forms a stable population in the urban areas under study. Throughout their lives, individuals from these populations are exposed to stress factors typical of cities, which may have reduced their reactivity to such stimuli.

The results obtained for A. flavicollis, however, could be explained by the hypothesis that the studied urban individuals do not come from a stable population that inhabits these areas on a permanent basis and may have migrated from places characterized by a lower intensity of stress factors. Higher noise levels or human proximity in urban areas may be the reason behind the elevated levels of corticosterone and less homogenous behavioral reactions observed for at least some of the parameters under study. Such conclusions are consistent with the current findings of population studies, which show that the urban populations of $A$. agrarius are in very good condition and certain indicators are better than those observed in the non-urban population under study. Meanwhile, individuals from the urban population of $A$. flavicollis are in much worse condition and it cannot be said that they form a stable urban population [34]. Similarly, genetic tests recently conducted among the same populations show that the urban populations of $A$. agrarius showed a high level of genetic differentiation and were strongly isolated, while gene flow from non-urban populations was not large [16] [17]. As for the urban populations of A. flavicollis, it was demonstrated that 
they included individuals that have migrated from different directions [20].

Different sensitivities to stress factors may have significant consequences for the potential to inhabit urban environments. Prolonged increased activity of the HPA axis may cause chronic stress, which may significantly impair the functioning of animals, including by reducing their reproductive capacity. In consequence, this may reduce reproductive success and winter survival, which means reduced chances of forming a stable population. It would be very interesting to test whether these species differ in their sensitivity to stress factors in natural populations. A species that is less sensitive to stress stimuli would stand a better chance of adapting to urban conditions. The results concerning grooming behavior could potentially indicate that $A$. agrarius is such a species.

It is also clear that sensitivity to stress factors may change when an animal is frequently exposed to such stimuli. Recent studies conducted on laboratory rats show that animals exposed repeatedly to stress factors show reduction in the response of the HPA axis. It was demonstrated that this change exhibited no characteristics typical of habituation, but it was suggested that it might involve learning processes [35].

A. flavicollis are naturally found in forests, where they actively utilize both the floor and canopy layers of vegetation and can easily climb shrubs and trees [18]. For that reason, both horizontal and vertical exploration is a typical way of examining the surroundings among individuals from this species. In turn, $A$. agrarius usually inhabits fields and meadows and moves chiefly on the surface of the ground [18]. This is why it is possible to conclude that the results concerning wall-leaning behavior for non-urban groups in both species reveal elements of exploration typical of these species. For A. agrarius from the urban populations, increased vertical exploration may be attributed to adaptation to the urban environment. As a result of the presence of numerous small barriers created by humans in cities (such as fences and curbs), the animals needed to extend this component of exploration in order to make use of the environment more effectively.

Open field tests are usually carried out on laboratory rodents; the few tests conducted on wild species are done with laboratory-born animals or animals maintained in laboratory conditions for extended periods of time [21] [36] [37]. Such animals are accustomed to being in relatively small cages. After they are placed into the test arena, their behavior is largely linked to novelty exploration. The animals in the present experiment were taken directly from the natural environment and underwent testing after a short period of acclimation. The arena used for the tests, although larger than those typically used in tests on small rodents, was many times smaller than the home range of the test rodents. After they were placed into the test arena, this was probably why they quickly explored the area and then attempted to escape. The studied species inhabit different environments, so they also seek refuge and attempt to escape in different ways, which was reflected in their behavior. The behavior of $A$. agrarius was dominated by digging, whereas $A$. flavicollis made significantly more jumps.

It should be emphasized, that current study was carried out on selected popu- 
lations of examined species. Their history of dwelling urban areas could not be representative for the whole species. Also observed differences in the distribution of behavioral parameters could be explained both by species-specific traits and urban inhabitation time-related factors. Further studies are necessary for a full understanding of observed phenomena.

\section{Conclusion}

In behavioral terms, the urban population of Apodemus agarius did not differ from the population that inhabited the environment natural for this species. This may indicate adaptation to higher levels of stress factors characteristic of cities. In the second species under study, namely Apodemus flavicollis, individuals from the urban population showed a different pattern of reactions in the tests compared to the population from the natural environment. In addition, those mice exhibited a higher level of stress, as demonstrated by higher corticosterone levels. This may attest to difficulties in adapting to urban conditions and explain the lack of stable urban populations.

\section{Acknowledgements}

The study was carried out at the Biological and Chemical Research Centre, University of Warsaw, established within the project co-financed by European Union from the European Regional Development Fund under the Operational Programme Innovative Economy, 2007-2013. The study was supported by the Ministry of Science and Higher Education through the Faculty of Biology, University of Warsaw intramural grant DSM \# 140000/501/86-107436.

\section{References}

[1] Werner, P. (2011) The Ecology of Urban Areas and Their Functions for Species Diversity. Landscape and Ecological Engineering, 7, 231-240. https://doi.org/10.1007/s11355-011-0153-4

[2] O'Leary, R. and Jones, D.N. (2006) The Use of Supplementary Foods by Australian Magpies Gymnorhina tibicen: Implications for Wildlife Feeding in Suburban Environments. Austral Ecology, 31, 208-216. https://doi.org/10.1111/j.1442-9993.2006.01583.x

[3] Møller, A.P., Diaz, M., Flensted-Jensen, E., Grim, T., Ibáñez-Álamo, J.D., Jokimäki, J., Mänd, R., Markó, G. and Tryjanowski, P. (2012) High Urban Population Density of Birds Reflects Their Timing of Urbanization. Oecologia, 170, 867-875. https://doi.org/10.1007/s00442-012-2355-3

[4] Munshi-South, J. and Kharchenko, K. (2010) Rapid, Pervasive Genetic Differentiation of Urban White-Footed Mouse (Peromyscus leucopus) Populations in New York City. Molecular Ecology, 19, 4242-4254. https://doi.org/10.1111/j.1365-294X.2010.04816.x

[5] Ditchkoff, S.S., Saalfeld, S.T. and Gibson, C.J. (2006) Animal Behavior in Urban Ecosystems: Modifications Due to Human-Induced Stress. Urban Ecosyst, 9, 5-12. https://doi.org/10.1007/s11252-006-3262-3

[6] Warren, P.S., Katti, M., Ermann, M. and Brazel, A. (2006) Urban Bioacoustics: It's Not Just Noise. Animal Behaviour, 71, 491-502. 
https://doi.org/10.1016/j.anbehav.2005.07.014

[7] Barber, J.R., Crooks, K.R. and Fristrup, K.M. (2010) The Costs of Chronic Noise Exposure for Terrestrial Organisms. Trends in Ecology and Evolution, 25, 180-189. https://doi.org/10.1016/j.tree.2009.08.002

[8] de Kloet, E.R. (2013) Functional Profile of the Binary Brain Corticosteroid Receptor System: Mediating, Multitasking, Coordinating, Integrating. European Journal of Pharmacology, 719, 53-62. https://doi.org/10.1016/j.ejphar.2013.04.053

[9] Myers, B., McKlveen, J.M. and Herman, J.P. (2014) Glucocorticoid Actions on Synapses, Circuits, and Behavior: Implications for the Energetics of Stress. Frontiers in Neuroendocrinology, 35, 180-196. https://doi.org/10.1016/j.yfrne.2013.12.003

[10] Korte, S.M. (2001) Corticosteroids in Relation to Fear, Anxiety and Psychopathology. Neuroscience and Biobehavioral Reviews, 25, 117-142. https://doi.org/10.1016/S0149-7634(01)00002-1

[11] Wałecki, A. (1881) Fauna zwierząt ssących Warszawy i jej stosunek do fauny całego kraju. Pamiętnik Fizjograficzny, 1, 268-291. (In Polish)

[12] Sumiński, S.M. (1922) Fauna of Warsaw. Ziemia, 12, 328-335. (In Polish)

[13] Andrzejewski, R., Babińska-Werka, J., Gliwicz, J. and Goszczyński, J. (1978) Synurbization Processes in Population of Apodemus agrarius I. Characteristics of Populations in an Urbanization Gradient. Acta Theriologica, 23, 341-358. https://doi.org/10.4098/AT.arch.78-24

[14] Gliwicz, J. (1980) Ecological Aspects of Synurbization of Striped Field Mouse, Apodemus agrarius (Pall.). Wiadomosci Ekologiczne, 262, 117-124.

[15] Liro, A. (1985) Variation in Weights of Body and Internal Organs of the Field Mouse in Gradient of Urban Habitats. Acta Theriologica, 30, 359-377. https://doi.org/10.4098/AT.arch.85-26

[16] Gortat, T., Rutkowski, R., Gryczynska-Siemiatkowska, A., Kozakiewicz, A. and Kozakiewicz, M. (2013) Genetic Structure in Urban and Rural Populations of Apodemus agrarius in Poland. Mammalian Biology, 78, 171-177. https://doi.org/10.1016/j.mambio.2012.07.155

[17] Gortat, T., Rutkowski, R., Gryczyńska, A., Pieniążek, A., Kozakiewicz, A. and Kozakiewicz, M. (2015) Anthropopressure Gradients and the Population Genetic Structure of Apodemus agrarius. Conservation Genetics, 16, 649-659. https://doi.org/10.1007/s10592-014-0690-0

[18] Pucek, Z. (1984) Keys to Vertebrates of Poland: Mammals. PWN, Warszawa, 357.

[19] Babińska-Werka, J. and Malinowska, B. (2008) Synurbization of the Yellow-Necked Mouse A. flavicollis in Warsaw. In: Indykiewicz, P., Jerzak, L. and Barczak, T., Eds., Fauna of Cities. Preservation of Biodiversity in Cities, ATR, Bydgoszcz, 144-150. (In Polish with English Abstract)

[20] Gortat, T., Rutkowski, R., Gryczynska, A., Kozakiewicz, A. and Kozakiewicz, M. (2016) The Spatial Genetic Structure of the Yellow-Necked Mouse in an Urban Environment-A Recent Invader vs. a Closely Related Permanent Inhabitant. Urban Ecosystems, 1-14. https://doi.org/10.1007/s11252-016-0620-7

[21] Frynta, D. (1994) Exploratory Behaviour in 12 Palaearctic Mice Species (Rodentia: Muridae): A Comparative Study Using "Free Exploration" Tests. Acta Societatis Zoologicae Bohemicae, 57, 173-182.

[22] R Core Team (2016) R: A Language and Environment for Statistical Computing. R Foundation for Statistical Computing, Vienna. https://www.R-project.org/

[23] Pohlert, T. (2014) The Pairwise Multiple Comparison of Mean Ranks Package (PMCMR). R Package. http://CRAN.R-project.org/package=PMCMR 
[24] Larsson, F., Winblad, B. and Mohammed, A.H. (2002) Psychological Stress and Environmental Adaptation in Enriched vs. Impoverished Housed Rats. Pharmacology Biochemistry and Behavior, 73, 193-207. https://doi.org/10.1016/S0091-3057(02)00782-7

[25] Brenes, J.C., Padilla, M. and Fornaguera, J. (2009) A Detailed Analysis of OpenField Habituation and Behavioral and Neurochemical Antidepressant-Like Effects in Postweaning Enriched Rats. Behavioural Brain Research, 197, 125-137. https://doi.org/10.1016/j.bbr.2008.08.014

[26] Montiglio, P.O., Garant, D., Thomas, D. and Réale, D. (2010) Individual Variation in Temporal Activity Patterns in Open-Field Tests. Animal Behaviour, 80, 905-912. https://doi.org/10.1016/j.anbehav.2010.08.014

[27] Perals, D., Griffin, A.S., Bartomeus, I. and Sol, D. (2017) Revisiting the Open-Field Test: What Does It Really Tell Us about Animal Personality? Animal Behaviour, 123, 69-79. https://doi.org/10.1016/j.anbehav.2016.10.006

[28] Prut, L. and Belzung, C. (2003) The Open Field as a Paradigm to Measure the Effects of Drugs on Anxiety-Like Behaviors: A Review. European Journal of Pharmacology, 463, 3-33. https://doi.org/10.1016/S0014-2999(03)01272-X

[29] Ennaceur, A. (2014) Tests of Unconditioned Anxiety-Pitfalls and Disappointments. Physiology and Behavior, 135, 55-71.

https://doi.org/10.1016/j.physbeh.2014.05.032

[30] Komorowska, J. and Pisula, W. (2003) Does Changing Levels of Stress Affect the Characteristics of Grooming Behavior in Rats? Joanna. International Journal of Comparative Psychology, 16, 237-246.

[31] Estanislau, C. (2012) Cues to the Usefulness of Grooming Behavior in the Evaluation of Anxiety in the Elevated Plus-Maze. Psychology and Neuroscience, 5, 105 112. https://doi.org/10.3922/j.psns.2012.1.14

[32] Veloso, A.W.N., Filgueiras, G.B., Lorenzo, P. and Estanislau, C. (2016) Modulation of Grooming Behavior in Rats by Different Test Situations. Psychology and Neuroscience, 9, 91-104. https://doi.org/10.1037/pne0000038

[33] Courtin, J., Bienvenu, T.C.M., Einarsson, E. and Herry, C. (2013) Medial Prefrontal Cortex Neuronal Circuits in Fear Behavior. Neuroscience, 240, 219-242. https://doi.org/10.1016/j.neuroscience.2013.03.001

[34] Pieniążek, A., Sokół, M. and Kozakiewicz, M. (2017) Ecological Characteristics of Two Closely Related Rodent Species in Urban Environment-Permanent Inhabitant vs Newcomer. Natural Resources, 8. (To be published)

[35] Rabasa, C., Gagliano, H., Pastor-Ciurana, J., Fuentes, S., Belda, X., Nadal, R. and Armario, A. (2015) Adaptation of the Hypothalamus-Pituitary-Adrenal Axis to Daily Repeated Stress Does Not Follow the Rules of Habituation: A New Perspective. Neuroscience and Biobehavioral Reviews, 56, 35-49. https://doi.org/10.1016/j.neubiorev.2015.06.013

[36] Frynta, D. (1992) “Open Field” Behaviour in Seven Mice Species (Muridae: Apodemus, Mus). In: Horáček, I. and Vohralík, V., Eds., Prague Studies in Mammalogy, Karolinum-Charles University Press, Praha, 31-38.

[37] Eilam, D. (2003) Open-Field Behavior Withstands Drastic Changes in Arena Size. Behavioural Brain Research, 142, 53-62. https://doi.org/10.1016/S0166-4328(02)00382-0 
Submit or recommend next manuscript to SCIRP and we will provide best service for you:

Accepting pre-submission inquiries through Email, Facebook, LinkedIn, Twitter, etc. A wide selection of journals (inclusive of 9 subjects, more than 200 journals)

Providing 24-hour high-quality service

User-friendly online submission system

Fair and swift peer-review system

Efficient typesetting and proofreading procedure

Display of the result of downloads and visits, as well as the number of cited articles Maximum dissemination of your research work

Submit your manuscript at: http://papersubmission.scirp.org/

Or contact nr@scirp.org 